\title{
Stop Smoking Service Clients' Views Following the Introduction of Smoke-Free Legislation in England
}

\author{
Lucy Hackshaw, ${ }^{1}$ Linda Bauld, ${ }^{2}$ and Andy McEwen ${ }^{3}$ \\ ${ }^{1}$ University of Nottingham, UK \\ 2 University of Stirling, UK \\ ${ }^{3}$ University College London, UK
}

\begin{abstract}
$T^{\text {n }}$ his study aimed to explore smoker's perspectives of continued smoking and smoking cessation following the introduction of smoke-free legislation in England. Seventeen semi-structured interviews were conducted with smokers who were making a quit attempt with the support of stop smoking services delivered by the National Health Service. Interviews explored opinions of smoke-free legislation before it was implemented in July 2007, as well as attitudes towards the legislation, beliefs about the influence of legislation on smoking behaviours, as well as changes to public attitudes about smoking. Framework analysis highlighted five key themes: attitudes towards smoke-free legislation prior to its introduction, support for smoke-free legislation following implementation, smoke-free legislation and smoking behaviour, stigma, and returning to smoking. Overall, smokers were positive about smokefree legislation and reported reductions in smoking and an increase in quit attempts after introduction of the legislation. Change in attitudes towards smoking and smokers were noted, which at times could transpire to stigmatisation felt by the participants. Few quitters expressed a wish to return to smoking if the legislation was reversed.
\end{abstract}

Keywords: cessation, smoke-free legislation, qualitative interviews

There is good evidence from around the world that the introduction of smoke-free legislation can lead to changes in smoking behaviour. In The Republic of Ireland, 46\% of smokers said that they were more likely to quit and $60 \%$ were more likely to cut down following implementation of smoke-free legislation (Fong et al., 2006). Of those smokers who had quit post-legislation, $80 \%$ said the law had helped them to quit and $88 \%$ said that it had helped then to stay abstinent (Fong et al.). In Norway, a reduction in prevalence was found in smoking employees, and the numbers of smokers attempting to quit increased significantly (Lund, 2007). In New Zealand, socially cued smoking substantially declined, and calls to quit lines increased following introduction of smoke-free legislation (Edwards et al., 2008). In Scotland, calls to the national quit line considerably increased (Howie, Harrell, \& O'Brien, 2006), and there was an increase in the numbers of smokers trying to give up (Fowkes, Stewart, Fowkes, Amos, \& Price., 2008). Evidence implies that smoke-free legislation may have a positive effect upon smoking behaviour and can lead to an increase in smoking cessation (International Agency for Research on Cancer (IARC), 2009).

Smoke-free legislation prohibiting smoking in enclosed public places and workplaces was introduced in England in July 2007 (Health Act, 2006). This led to an increase in reported quit attempts (Hackshaw, McEwen, West, \& Bauld, 2010). However, little is known about the dynamics of this prompted behaviour change.

\section{Apprehension About Smoke-Free Legislation}

When the Health Act (2006) was passed and it was announced that England would go smoke-free on July 1, 2007, there was a mixed response among the general public. A qualitative study of the impact of smoke-free 
legislation, conducted by Platt et al. (2009), highlighted the initial scepticism and negativity expressed by certain groups within society, such as younger smokers, as well as older established smokers. Some members of the public did not believe the research on the effects of second-hand smoke, and thus did not understand the need for the smoke-free legislation (Platt et al.). Some of these smokers, who held negative opinions about the forthcoming legislation, also felt that it would not have an impact upon them, and others felt that they would be able to avoid or ignore the new restrictions (Platt et al.). This was not the case with all smokers however, as many were positive and optimistic about the new legislation, seeing it as a way to help them to cut down or quit (Platt et al.).

\section{Support for Smoke-Free Legislation}

Smoke-free policies have been popular among smokers and nonsmokers alike, and appear to be more popular after the legislation is introduced. Public opinion polls in England at the time of implementation suggested that there was only a small proportion of the public who objected to the smoke-free legislation (ONS, 2008a). However, despite this opposition, the new law was implemented smoothly and successfully, with less animosity than expected. ONS data from the 2007 Omnibus Survey concluded that 80\% of respondents 'strongly agreed' and 'agreed' with the legislation; only 20\% 'disagreed' and 'strongly disagreed' with the legislation (ONS, 2008a). Hilton, Cameron, MacLean, and Petticrew (2008) conducted in-depth interviews with bar staff to explore their perceptions of patrons' behaviour following the introduction of smoke-free legislation in Scotland, and concluded that patrons readily accepted and complied with the new law.

Fowkes et al. (2008) interviewed smokers following the introduction of the Scottish smoke-free legislation. They found that over $70 \%$ of smokers interviewed considered the smoke-free legislation to be positive. However, the researchers also suggested that smokers from the more deprived areas of Scotland were less positive about the legislation than those from more affluent areas. Donnelly and Whittle (2008) also conducted an evaluation of the Scottish smoke-free legislation and found that $84 \%$ felt that the legislation was 'something to be proud of, and $73 \%$ thought the legislation was 'successful' or 'very successful'. Platt et al. (2009) concluded that many participants shifted their attitude towards the new law, from broadly negative prelegislation to more positive postlegislation.

\section{Behaviour Change and Smoke-Free Legislation}

Smoke-free legislation is primarily aimed at reducing exposure to second-hand smoke. However, it can also facilitate quit attempts (Hackshaw et al., 2010) and make smoking less socially acceptable. Information Centre data in England showed that there was a 22\% increase in the number of people successfully quitting, at 4 weeks, and a $23 \%$ increase in the number of people setting a quit date through the stop smoking services in 2007/8 compared with the same period in 2006/7 (Department of Health, 2008). Platt et al. (2009) suggested that many smokers, in particular more affluent smokers, expected the legislation to have a positive impact upon their smoking behaviour, helping them to cut down or quit altogether. They found, however, that other smokers, especially those who were older and less affluent, felt that the legislation had not had an impact upon their smoking behaviour (Platt et al., 2009).

Following the implementation of the Scottish smokefree legislation, calls to the smoking cessation helpline increased threefold (Howie et al., 2006) and there was a substantial rise in the demand for help to quit smoking (Donnelly \& Whittle, 2008). Fowkes et al. (2008) found that in the year that the legislation was introduced in Scotland, there was a change in the pattern of quitting with an increased proportion of smokers quitting in the three months prior to the legislations introduction.

\section{Smoke-Free Legislation Related Stigma}

Research suggested that members of the public, including both smokers and nonsmokers, rapidly adapted to the legislation, acknowledging the benefits and often showing little sympathy for arguments against it (Platt et al., 2009). Hilton et al. (2008) found that some smokers experienced feelings of exclusion, and it was suggested that smokers were set apart from mainstream nonsmoking society; describing one smoker who referred to smokers, including himself, as 'the unclean'. It was also commented upon that older, more frail smokers were unable to easily leave the bar to socialise with other smokers and were therefore being excluded from their social network (Hilton et al.). Platt et al. acknowledged similar attitude changes in England, where smokers felt uncomfortable and found it difficult to smoke outside, thus on occasion leading to exclusion, distress and resentment, in particular among those who were of an older age.

Platt and colleagues' research (2009) suggested that there was a social stigmatisation attached to smoking. They highlighted that some smokers felt discomfort while smoking outside and did not wish to be identified as a smoker. Some smokers talked about feeling embarrassed and awkward, and that going outside to smoke felt degrading. To overcome this, smokers often cut down how much they socialised, how much they smoked while out socialising or smoked when walking between venues, as opposed to leaving a bar to go outside for a cigarette. Participants in Platt et al.'s research discussed situations where members of the public had made comments towards them in the street, in public parks and other locations where smoking was allowed, telling them it was 'a disgusting habit and that they should quit'. Platt et al. concluded that smoking had become less socially acceptable and that this attitude shift had largely been encouraged and exacerbated by the smoke-free legislation. 
Table 1

Sample Characteristics

\begin{tabular}{|c|c|c|c|c|c|c|}
\hline Name & Sex & Age (years) & Marital status & Highest education level & $\begin{array}{l}\text { Current employment } \\
\text { status }\end{array}$ & Time since last cigarette \\
\hline Abigail $^{\circ}$ & $\mathrm{F}$ & $31-40$ & Married & Undergraduate degree & Employed & Unknown \\
\hline Bella $^{\circ}$ & $\mathrm{F}$ & $41-50$ & Single / never been married & GCSE or equivalent & Employed & Unknown \\
\hline Charlotte & $\mathrm{F}$ & $41-50$ & Single / never been married & GCSE or equivalent & Employed & Unknown \\
\hline Daisy & $\mathrm{F}$ & $52-60$ & Divorced & Undergraduate degree & Out of work & 1 week \\
\hline Emily $^{*}$ & $\mathrm{~F}$ & $26-30$ & Living with partner & GCSE or equivalent & Employed & Still smoking \\
\hline Faye & $\mathrm{F}$ & $31-40$ & Living with partner & Less than secondary school & Unable to work & 3 days \\
\hline Georgina* & $\mathrm{F}$ & $22-25$ & Living with partner & GCSE or equivalent & Out of work & 3 days \\
\hline Hazel & $\mathrm{F}$ & $51-60$ & Married & Less than secondary school & Unable to work & 3 days \\
\hline Imogen & $\mathrm{F}$ & $41-50$ & Divorced & GNVQ, A level or equivalent & Self-employed & Unknown \\
\hline Jack & M & $41-50$ & Married & Less than secondary school & Self-employed & 1 week \\
\hline Kevin & M & $31-40$ & Divorced & GNVQ, A level or equivalent & Out of work & 1 day \\
\hline Lydia & $\mathrm{F}$ & $51-60$ & Married & Less than secondary school & Housewife & 3 weeks \\
\hline Mark & M & $71+$ & Divorced & Less than secondary school & Retired & Unknown \\
\hline Nick & M & $61-70$ & Single/never been married & GCSE or equivalent & Retired & 2 weeks \\
\hline Oscar & M & $22-25$ & Living with partner & GNVQ, A level or equivalent & Employed & Still smoking \\
\hline Paul & M & $61-70$ & Married & Less than secondary school & Retired & 3 weeks \\
\hline Shane & $M$ & $18-21$ & Living with partner & GNVQ, A level or equivalent & Employed & Still smoking \\
\hline
\end{tabular}

Note: ${ }^{\circ}$ Participant with a circle by their name $=$ pilot interview.

"Participant with a star by their name $=$ pregnant at time of interview.

\section{Stop Smoking Services Client's Perspectives of Smoke-Free Legislation}

The United Kingdom has a national treatment service for smokers, paid for by taxation and free at the point of use and available through the National Health Service (NHS) since 1999. These NHS Stop Smoking Services (SSS) offer cessation medication and behavioural support for people who wish to stop smoking. It was predicted that the English smoke-free legislation would have an impact upon smoking behaviours and attitudes of NHS SSS clients.

Therefore, this study set out to gather knowledge about the experience of quitting smoking from a smoker's perspective and to explore the implications of the smoke-free legislation for those people who were trying to quit smoking.

\section{Method}

This article reports data taken from a larger piece of research which explored the implications of the English smoke-free legislation for NHS stop smoking services (NHS SSSs; Hackshaw, 2010). For the purpose of this article, results focus upon the experiences of smoking cessation following the introduction of smoke-free legislation in England for people making a quit attempt.

The current research was conducted with clients attending an NHS SSS in a city in the south-west of England. Although there are areas of affluence, overall it is a relatively deprived city (ONS, 2008a). At the time of the research, the area's smoking prevalence was $24 \%$, higher than the English national average of 22\% (ONS, 2008b).

Ethical approval was sought and gained from the NHS Integrated Research Application System. In addition to ethical approval, local site specific approval was also granted from the Primary Care Trust where the research was to be conducted.

\section{Sample}

Semistructured interviews were conducted with 17 SSS clients who were in the process of quitting smoking. Of the sample, $58 \%(n=10)$ were female. The mean age was 43 years, 35\% $(n=6)$ were living with their partner, and a further $29 \%(n=5)$ were married. Twenty-four per cent $(n=4)$ of the sample were divorced and $12 \%(n=2)$ were single or had never been married. Over a third of the participants $(35 \%, n=6)$ had a less than secondary school education, meaning that they had left school without formal qualifications. In total, $35 \%(n=6)$ of participants were employed, $18 \%(n=3)$ were out of work, and a further $18 \%(n=3)$ were retired. The average length of time that the participants had not smoked for was 1 week; however, three of the sample were still smoking. For five of the participants who had recently stopped smoking, it was unknown how long they had been stopped for at the time of interview. Sample characteristics can be seen in Table 1. 


\section{Interviews}

Data collection took place in November 2008. The researcher shadowed the SSS team and opportunity sampling occurred. The final interview locations were; six in a quiet office in the SSS headquarters, one in a clinic following a group cessation session, four home visits and six at a city centre drop in. All interviews were conducted on a one-to-one basis, except in two circumstances where there were two participants at a time. In these cases they were mother and daughter, and a married couple.

Clients were asked what had been their opinions of smoke-free legislation before it was implemented, as well as their current attitudes towards it. They were asked whether they believed that nonsmokers thought differently about smokers as a result of the smoke-free legislation. Clients were additionally asked whether they would return to smoking if it were no longer harmful or if the smoke-free legislation were reversed. Two pilot interviews were conducted with recent ex-smokers; this was to ensure that the questions were clear, that they were able to access the required information, and that the demographic questions were suitable. No significant adaptations were suggested. Data collected in these interviews were included in the main analysis.

\section{Analysis}

All interviews were recorded on a digital voice recorder and downloaded onto a computer. The interviews were transcribed and each participant was given a pseudonym. The letter $\mathrm{R}$ in the transcriptions represented where the researcher was speaking. Framework analysis (Ritchie \& Spencer, 2002) was used to explore, understand and interpret the data. The transcripts were analysed with the assistance of NVivo version 8.

\section{Findings}

Five key themes emerged: attitudes towards smoke-free legislation prior to its introduction, support for smokefree legislation following implementation, smoke-free legislation and smoking behaviour, stigma, and returning to smoking.

\section{Attitudes Towards Smoke-Free Legislation Prior to its Introduction}

The current research, to some extent, supported the findings of Platt and colleagues (2009) who suggested that certain groups within society were initially opposed to smoke-free legislation. Clients in the current research demonstrated mixed initial opinions towards the smokefree legislation. The interviewees were asked how they felt about the legislation before it was implemented. Only one participant was initially 'neither positive nor negative'. Participants appeared to initially feel either one way or the other about the legislation.

The nine participants who responded in a positive manner commented upon aspects such as it creating a cleaner atmosphere inside pubs and restaurants, that it would be healthier for workers, especially within the hospitality industry, and that they understood the dangers of second-hand smoke, so it was fairer on nonsmokers. Many of the participants stated that although they were a smoker themselves, they disliked being in smoky environments; the legislation was therefore positive, as summarised by Abigail:

I thought it was a really good idea ... because it was just very unpleasant to be in, even though I was a smoker, I didn't like sitting in smoky rooms because of your hair, your clothes, watering eyes, all of that kind of stuff, I didn't like sitting in rooms that were full of smoke.

In comparison, seven of the interviewees said that their initial reaction to the smoke-free legislation was negative; highlighting that they were concerned about having to smoke outside on wet and windy nights and that people may look down on them while they were smoking outside. Oscar talked about how he and his friends were concerned that they would not be able to smoke, and thought that everyone would stay at home instead of going to the pub. Faye described it as rotten, saying that she felt persecuted. The quote from Kevin below was similar to many of the participants:

Didn'tparticularly like it. Didn't like the idea, especially because I was an active drinker at the time ... And the thought of standing outside in the rain doesn't bode well with anybody I don't think.

\section{Support for Smoke-Free Legislation Following Implementation}

Findings by Fowkes et al. (2008), Donnelly and Whittle (2008), and Platt et al. (2009), that despite some initial negative attitudes towards smoke-free legislation, many people responded in a positive manner once implemented, were echoed in the current research. Participants' initial opinions of smoke-free legislation were equally split between positive and negative attitudes. When asked how they currently felt about the legislation, only two participants expressed negative opinions, and those illustrating a positive attitude had increased in number. Three of the participants showed a mixed attitude, suggesting that overall they were 'neither positive nor negative' towards the legislation.

What was of most interest within this theme was the reaction of the participants whose attitudes changed between pre- and post-legislation. Kevin, for example, had initially been anti the legislation; however, his attitude changed once he realised it wasn't as bad as he had expected it to be.

$$
\begin{aligned}
& R \quad \text { So your attitude changed quite a lot then from before it } \\
& \text { came in? } \\
& K \quad \text { Yes. In a very positive way. It didn't take long either. I was } \\
& \text { expecting months and months and months but it didn't take } \\
& \text { long, maybe a week or so, and I thoroughly agree with it now. }
\end{aligned}
$$

This extract illustrated not only the extent of Kevin's attitude change, but also the speed in which the change 
occurred. Paul also experienced a change in opinion towards the legislation, although this change appeared to take slightly more time.

We got used to it after a month or so didn't we? ... and we used to go outside, after the coffee, we'd go outside and have a fag ... but now we think it's the best thing that's happened ... because now you can go into a café knowing that no one's going to be fagging it ... sit down and have a coffee and have something to eat and taste it without people coughing and spluttering. (Paul)

\section{Smoke-Free Legislation and Smoking Behaviour}

Analysis from the current research suggested that the smoke-free legislation did have an impact upon smoker's behaviour; in particular, the level of smoking and quitting behaviour. These results support previous findings by Hackshaw et al. (2010), Department of Health (2008), Platt et al. (2009), Howie et al. (2006), Donnelly and Whittle (2008) and Fowkes et al. (2008).

Six of the clients interviewed discussed how the smokefree legislation had made them cut down the amount of cigarettes that they smoked. The most commonly cited reason for this was it being cold outside, so they did not want to stay outside for very long. One participant said that he used to smoke half of a cigarette and then go back inside. Another reason suggested for cutting down was by a taxi driver who said that she could no longer smoke inside the cab as she normally would, and that she could not be bothered to get out and smoke while waiting for a job.

In contrast, one participant said that he smoked more because of the legislation; he said that if he went outside to smoke, he would chain smoke a few to make the trip outside worthwhile. Another participant said that although she was smoking less, she felt that she was drinking more alcohol as a substitute.

I think I smoked less if I went out, I smoked less and drank more because it's cold outside and stay indoors, yeah, I smoked less and that, but then cos you got a drink in your hand and so you're doing something and that with your hand, instead of having a fag in your hand. (Emily)

Two of the participants said that the legislation had been part of the reason that they decided to stop smoking.

Part of the reason towards it, knowing that I couldn't smoke in the premises gave me an extra incentive as well, it was positive, yes, yes. (Jack)

More often, clients stated that the legislation had made it easier to remain abstinent, and therefore had made their quit attempts easier. Some said that they found it supportive that they could not light a cigarette and start smoking where they were sitting, and that it became a conscious decision to go outside and smoke.

Well, yeah, yeah, yeah, it will help me quit cos that's the main reason why I've actually cut down, I haven't been able to go into a pub and sit down, you go in get your pint and go outside in the freezing cold and it's like your outside and it's like I don't wanna go outside. I can't be arsed to go out for another fag. (Shane)
They also suggested that without being surrounded by other people who were smoking, they were less tempted to return to smoking.

It was interesting that despite many participants talking about how the legislation had impacted upon their smoking behaviour, nine of them also made comments about how it had had no impact upon their smoking behaviour. They talked about how pubs had been accommodating and put heaters in the seating areas outside for the smokers; others said that there were more people outside smoking than sitting inside, so it became quite sociable to be outside.

\section{Stigma}

Following the introduction of the smoke-free legislation, it was anticipated by some that there would be a change in general attitudes towards smoking. As with previous research (Platt et al., 2009; Hilton et al., 2008), the current research explored the participants' opinions about society's attitudes to smoke-free legislation, smokers and smoking generally. The clients largely confirmed the findings of previously mentioned research, with similar issues, opinions and experiences being focused upon.

It became apparent that many of the participants disliked smoking, found the smell unpleasant, did not think it looked very attractive, and did not enjoy spending time in a smoky environment. Many of them seemed to be positive about the legislation as they felt it would improve the environment in public places. These comments were not restricted to those who had already stopped smoking. An example of this was seen below with Kevin, who was thinking about stopping smoking:

It's no good, and it's nasty. I don't particularly like it anymore ... I'm at the stage now where I dislike smoking a lot. I'm doing it because it's a habit.

One participant, Daisy, stated that smoker's did not like smoking or enjoy smoking:

Every single person that I've met who's a smoker wishes they hadn't started. That's all I can tell you, not a single person that I've ever had that conversation with has said 'Oh I don't mind, I'm quite glad I started'.

Despite showing disdain towards smoking, the majority of interviewees did not express any negative attitudes towards actual smokers. Some of them implied that they felt sorry for people who smoked and often explained that this was because they knew how easy it was to initiate the behaviour and how difficult it was to stop. This was summarised by Charlotte, who had quit smoking for a period of time, before returning to her addiction:

When I wasn't smoking and I saw other people smoking around me, I just thought shame, you should give it up really, but now that I'm back to it, it's easy to see it, it's really hard to give up.

However, it appeared that some clients quickly took an anti-smoking stance and talked in a negative manner about smokers. For example, when Jack was smoking he 
did not mind seeing other people outside premises smoking; however, once he stopped smoking this changed:

I'd say the annoying part is seeing everybody outside smoking there and you've got to walk through to get into the premises ... all by the front door and that really annoys me. I mean they're not using the ashtrays neither, they're just putting it out on the floor.

There was considerable agreement with previous research (Platt et al., 2009; Hilton et al., 2008) in relation to how the current participants felt when smoking in public. Eight of the interviewees talked about being embarrassed to smoke outside, how they felt judged and that they could see people rolling their eyes at them, or looking down upon them. Here Georgina talked about how smoking in public made her feel:

You do feel as if like, you stand out in a crowd, like almost it's a weird feeling, but you feel, I don't know about anybody else, but you feel like dirty and stinky and just, ohhh, look at me outside.

In a similar way to Georgina, Paul discussed feeling uncomfortable when he smoked in public and how he tried to avoid this negative feeling. Paul explained how he used to only smoke around other smokers as it made him feel more comfortable about his own smoking behaviour:
$P \quad$ We'd go somewhere where someone else was smoking, like on a seat. You know, for instance, out by the bus stops, the seats, isn't it? And I look around to see who was smoking and I'd go and sit next to them
$R \quad$ Why is that?
$P \quad I$ don't know. Because then I know he was the same as me like, on the fags.

He continued to explain that if he was smoking and someone who was not smoking came and sat near him he would, in reverse of the previous behaviour, put the cigarette out.

I was sat down and a lady come up with her bags. I'd put the fag out and I'd go somewhere else later on. (Paul)

However, in contrast to this, three of the participants said that they had never noticed anybody talking about them or responding negatively towards them while they smoked outside. One explanation provided for this by Faye suggested that smokers sometimes ignored how others reacted to their smoking:

Sod our health, sod everybody else's health, yeah I think its more, it's a selfish habit, very selfish, because you're so hooked on it, you don't see what's around, you're just focused on having that fag in your hand.

Many of the participants talked about a change in societal attitudes towards smoking in recent years. Many of them reflected back to when they used to smoke in the past when smoking was generally accepted, in comparison with their more recent smoking experiences where they noticed how antisocial smoking had become. Some talked about how smokers' attitudes had changed and that they no longer expected to be able to smoke in the company of nonsmokers. Others talked about how smoking was now a thing of the past. As Abigail highlighted, these changes in attitude may not necessarily have been due to the smoke-free legislation; however, many of the participants attributed it to this.

Whether it was because of the legislation or whether it was changing anyway, certainly in the last year that I smoked, you could see peoples' attitudes were different I think ... in that it was much more frowned upon in a social situation. (Abigail)

In line with previous research (Platt et al., 2009; Hilton et al., 2008), interviewees often told of negative responses they had received from the public towards their smoking or how the public generally responded to smokers. The interviewees talked about how people who didn't smoke probably saw it as a 'dirty filthy habit' and how they felt that people looked down upon others who smoked. One participant, Daisy, explained how in the past people either were or were not smokers and this was accepted by the public; however, that had changed.

It was much more acceptable: 'Oh you're a smoker, I'm not, but that's $O K$, you're a smoker' and now it's 'Ooh, there's a smoker'. (Daisy)

Three of the participants talked about what they felt societal opinions of the smoke-free legislation were. They all agreed that the general public were glad that smokers had to go outside to smoke, suggesting they would not have to 'put up' with smoking any more. Daisy expressed her opinion, as well as explaining what she had heard others saying about the situation:

I think the nonsmokers are just very relieved that they don't
have to breathe in somebody else's smoke anymore. That's the
impression I get from what I hear generally in conversation. You
know, I think they're just very glad that they can now go into
a pub, especially pubs and restaurants and public places, and
they know that it's going to be smoke-free.

There was a feeling that society in general was positive about the smoke-free legislation and that this had led to a change in attitude towards smoking being anti-social and smokers being to blame for their behaviour.

\section{Returning to Smoking}

The interviews explored what would make the SSS clients return to smoking once they had made a successful quit attempt. Two specific questions were asked, one asking whether they would return to smoking if smoking were not harmful, and the other asking whether they would return to smoking if the smoke-free legislation was reversed.

Just one participant, Bella, stated that she would return to smoking if it were no longer harmful to health; however, she highlighted that it would also have to be cheaper. Five participants said that they would not return to smoking and five said that they would consider returning to smoking.

Those who said they would not return to smoking stated that even if it was not harmful, other factors such as the unattractive smell, high cost and general dislike for smoking would stop them returning. 
Of the five interviewees who said that they would consider returning to smoking, almost all discussed the pros and cons of the behaviour.

That's a tough question that is. I don't know. Because I think we're still ... no. But it's a good question because at this minute we've done pretty well at the moment ... but there's always that little nag in the back of your head where 'cor I could do with a fag', but I mean that's a fleeting glance ... but its only going to take one cigarette ... I mean if you think 'Oh I'm going to have, I'll just have one puff and you think to yourself 'Well it's not going to do me any harm', go and buy 20. (Paul)

Although many smokers cited health as their primary reason for wishing to stop smoking, there were often other factors involved that would still lead them to cessation and prevent them from returning to smoking if the harmful elements were eliminated. The current findings differ to some extent from those of Vangeli, Sykes, and West (2008), who found that in their sample of recent exsmokers, over $40 \%$ would return to smoking if it was not harmful.

Of the seven participants who were asked whether they would return to smoking if the smoke-free legislation was reversed, there was a unanimous no. In terms of public health this was a positive and perhaps surprising response. Six of the seven participants gave a straightforward 'no' response to this question. Oscar discussed this in a little more detail; however, he came to the same conclusion:

No. Not now no ... if they said you're allowed to smoke inside now I don't think that would make a difference. I don't, I wouldn't go back to smoking, but it would make it harder if I'm in a room and people are smoking around me. Obviously that makes it harder but I don't think, hopefully, I wouldn't go back to it.

This provided further evidence for the theme 'Smokefree legislation and smoking behaviour', suggesting that the smoke-free legislation had led to a change in some smokers' overall opinions about smoking and smoking behaviours.

\section{Discussion}

The introduction of smoke-free legislation had important implications for recent ex-smokers and smokers in the process of quitting. Opinions and attitudes varied in relation to the smoke-free legislation and smoking in general. Initial opinions of smoke-free legislation in England varied from very positive to apprehensive. Many hoped it would lead to a reduction in their smoking and would create smoke-free environments, whereas others worried that it would disrupt their social networks and force them to smoke outside in all weather conditions. Following implementation, this changed to predominantly positive and supportive attitudes. This finding is supported by research that has focused upon public attitudes, compliance and support for the legislation in Scotland and England (ONS, 2008a; Fowkes et al., 2008; Platt et al., 2009). Platt and colleagues found similar patterns to those in the current client interviews. It was encouraging that, despite the limited size of the current sample, similar findings were reported in a large-scale longitudinal study.

The legislation led to a reduction in cigarette consumption for some participants and in some cases this resulted in a quit attempt. Smokers commonly reported that once a quit attempt had been initiated, the legislation had helped to maintain abstinence through the removal of smoking cues and by changing public attitudes towards smoking. Other research has reported similar findings (Howie et al., 2006; Department of Health, 2008; Platt et al., 2009). For example, Platt et al. found a general pattern of reduced consumption among the participants in their longitudinal study, with many cutting down and to a lesser extent quitting. An aim of the smoke-free legislation was to change public attitudes towards smoking and make smoke-free 'the norm'. Interviewees often reported that this was the case, confirming that their personal opinion of smoking had changed. Other research such as Hilton et al. (2008) and Platt et al. drew similar conclusions, suggesting this aim of the legislation was achieved.

Participants reported that attitudes towards smoking had changed around the time of the legislation's introduction and that it was becoming less socially acceptable to smoke. Participants stated that they disliked smoking and often felt judged when they smoked in public. It was suggested that the general public had adapted well to the legislation and that it was seen as a positive advance for public health.

Interviewees reported that if smoking was not harmful they would not return to smoking as there were other factors about smoking that they disliked. There was also a resounding 'no' when asked whether they would return to smoking if the smoke-free legislation was reversed.

\section{Limitations}

Those who agreed to participate in the research may have had different attitudes towards smoking cessation and the smoke-free legislation than those who did not agree to participate. The sample may therefore have been biased; however, of those asked to participate, only two refused, with time limitations being given as their explanation.

Clients were only recruited from one SSS, thus participants were from one area of England. Additionally, as previously stated, those who were attending the SSS may not have been a representative sample of all smokers in England and the sample size was relatively small. This therefore limited the ability to generalise the findings.

Clients were asked to recall how they felt about events that occurred 16 months prior to the interviews. This may have resulted in recall bias as they may have been unable to correctly remember how they felt about the specific events. However, this was inevitable as the smoke-free legislation needed to have been in place for a period of time in order for its implications to be evident. 


\section{Recommendations for Policy and Practice}

Smoke-free legislation can lead smokers to make a quit attempt as well as helping to maintain abstinence in those who have already quit. Other countries that are implementing smoke-free legislation could ensure that support is available to maximise any quitting potential and to help to bridge the gap between intention and behaviour for smokers in the population. Other countries have different support systems set up for smokers who wish to quit, so the increased support provided in England, along with other changes following the legislation cannot be mapped exactly onto other countries. However, lessons can be learned from the English experience, and if changes in smoking behaviour are expected, provisions should be in place to support this. For example, in countries with a cooler climate, it may be advantageous to introduce smoke-free legislation in winter, as this may deter people from moving outside to smoke, therefore leading them to cut down or make a quit attempt.

A range of tobacco control policies that continue to monitor tobacco use and protect individuals from the dangers of tobacco have now been implemented in the United Kingdom. This effort by the government, as well as that by researchers and health care professionals, must continue. This is of particular importance at the current time, with a new government and with the economic problems that England is currently facing. Keeping tobacco control on the political agenda will continue to save lives, save money for individuals, and help to reduce the gap in health inequalities. While people in England continue to put themselves and others in danger through smoking, there is still work to be done.

\section{Acknowledgments}

The authors thank the participants for their time and contributions to the research, and the SSS staff for their assistance setting up the interviews. Thanks to Cancer Research UK for funding the first authors PhD studentship, during which this research was conducted.

\section{References}

Department of Health. (2008). Smoke-free England — one year on. London: Author.

Donnelly, P., \& Whittle, P. (2008). After the smoke has cleared: Reflections on Scotland's tobacco control legislation. Public Health, 122, 762-766.

Edwards, R., Thomson, G., Wilson, N., Waa, A., Bullen, C., O'Dea, D., ... Woodward, A. (2008). After the smoke has cleared: Evaluation of the impact of a new national smoke-free law in New Zealand. Tobacco Control, 17, 211 .

Fong, G.T., Hyland, A., Borland, R., Hammond, D., Hastings, G., McNeill, A., ... Driezen, P. (2006). Reductions in tobacco smoke pollution and increases in support for smoke-free public places following the implementation of comprehensive smoke-free workplace legislation in the Republic of Ireland: Findings from the ITC Ireland/UK survey. Tobacco Control, 15, 51-58.

Fowkes, F.J.I., Stewart, M.C.W., Fowkes, G.R., Amos, A., \& Price, J.F. (2008). Scottish smoke-free legislation and trends in smoking cessation. Addiction, 103, 1888-1895.

Hackshaw, L.E. (2010). The implications of smoke-free legislation for National Health Service stop smoking services (Unpublished doctoral thesis). University of Bath, UK.

Hackshaw, L.E., McEwen, A., West, R., \& Bauld, L. (2010). Quit attempts in response to smoke-free legislation in England. Tobacco Control, 19, 160-164.

Health Act. (2006). Retrieved from http://www.opsi.gov.uk/ acts/acts2006/pdf/ukpga_20060028_en.pdf

Hilton, S., Cameron, J., MacLean, A., \& Petticrew, M. (2008). Observations from behind the bar: changing patrons' behaviours in response to smoke-free legislation in Scotland. BMC Public Health, 8, 238.

Howie, M., Harrell, E., \& O’Brien, R. (2006, March 31). Smoking ban sparks leap in efforts to quit. The Scotsman. Retrieved from http://thescotsman.scotsman.com/latestnews/ Smoking-ban-sparks-leapin. 2763234.jp

International Agency for Research on Cancer (IARC). (2009). Evaluating the effectiveness of smoke-free policies (Volume 13). Lyon: Author.

Lund, M. (2007). Smoke-free bars and restaurants in Norway. Oslo: SIRUS.

Office for National Statistics (ONS). (2008a). Widespread support for smoking ban. Newport, UK: Author.

Office for National Statistics (ONS). (2008b). Neighbourhood statistics. Retrieved from http://www.neighbourhood. statistics.gov.uk/dissemination/LeadKeyFigures

Platt, S., Amos, A., Godfrey, C., Martin, C., Ritchie, D., \& White, M. (2009). Evaluation of smoke-free England: A longitudinal qualitative study. London: Public Health Research Consortium. Retrieved from http://www.york.ac. uk/phrc/PHRC_A5-06\%20RFR.pdf

Ritchie, J., \& Spencer, L. (2002). Qualitative data analysis for applied policy research. In A.M. Huberman \& M.B. Miles (Eds.), The qualitative researchers companion (pp. 305-329). Thousand Oaks, CA: Sage.

Vangeli, E., Sykes, C., \& West, R. (2008, June-July). What smokers say about stopping and relapsing. Paper presented at the UK National Smoking Cessation Conference, Birmingham, UK. 